\title{
Un manuscrito inédito, La relifión natural, de un gran decimonónico, Francisco de Paula González Vigil
}

\section{Helí Córdova}

Universidad Científica del Sur

\section{RESUMEN}

Este artículo presenta el texto La relijión natural, manuscrito inédito de Francisco de Paula González Vigil, puesto en valor hace algunos años, gracias a las investigaciones realizadas por jóvenes sanmarquinos. El texto presenta una propuesta radical para alguien de su tiempo: dejar atrás el sistema dogmático de creencias para retornar a la religión natural, a la religión de Jesucristo, la que él fundó y no la que los hombres han edificado, que es intransigente e intolerante. González Vigil planteó en su último texto su testamento para la fe cristiana, que se sostiene en bases filosóficas bien cimentadas.

\section{PALABRAS CLAVE}

Religión natural, dogma, origen.

\section{ABSTRACT}

This article presents the text Natural Relijion, unpublished manuscript of Francisco de Paula González Vigil, put in value a few years ago, thanks to research by young San Marcos. The text presents a radical proposal for someone your time: Leave behind the dogmatic belief system to return to natural religion, the religion of Jesus Christ, which he founded and which men do not have built that is uncompromising and intolerant. González Vigil, in its latest won't text her will for the Christian faith, holding on wellgrounded philosophical bases.

\section{KEYWORDS}

Natural religion, dogma, origin. 
El doctor Francisco de Paula González Vigil es uno de los filósofos, juristas, políticos y pensadores de mayor relevancia del siglo XIX, y uno de sus principales núcleos intelectuales. Personaje de influencia liberal que produjo una crítica profunda tanto a la política conservadora de su entorno como a los dogmas y a la Iglesia católica. Esta crítica no tuvo precedentes en siglo XIX en el ámbito peruano, ni en el latinoamericano; además, tuvo una frontal y directa discusión epistolar con el Papa Pío IX. «Vigil es un autor muy completo que reflexionaba mucho sobre el sistema político. Es muy famoso por su lucha contra el autoritarismo de Gamarra y la defensa de la Constitución. Un republicano, un hombre vinculado a la política, que gana elecciones, que se pelea con todo el mundo, que es exiliado y excomulgado». Según lo hace notar el historiador Aljovín, en la entrevista que tiene en el diario El Comercio (2007: 6).

La importancia de este personaje es evidente $y$, por consiguiente, su obra, para la historia del pensamiento y la filosofía peruana. Por tanto, es imprescindible el rescate y sobre todo el análisis de este texto inédito para completar y estudiar a mayor profundidad las posturas ideológicas de este autor $y$, con él, la sociedad peruana del siglo XIX.

Vigil fue quien representó a aquellos hombres que en el Perú combatieron por la razón y la ciencia contra la fe y la ignorancia. Sería el verdadero precursor y el viejo soldado que allanó el camino, que luchó en la vanguardia, que dio y recibió los primeros golpes del sistema conservador peruano. Por la fortaleza de carácter, por la sinceridad de convicciones, por lo inmaculado de su vida, Vigil redime las culpas de toda una generación. No tuvo rivales ni dejó sucesores, y se distingue en el Perú como solitaria columna de mármol a orillas de río cenagoso (González Prada 1893).

Los últimos años ha tomado mayor relevancia su nombre, debido al hallazgo en el Fondo Reservado de la Universidad Nacional Mayor de San Marcos de un texto manuscrito intitulado La relijión natural. El texto fue donado por el doctor Alberto Ulloa Sotomayor, sobrino bisnieto del gran regalista, en las primeras décadas del siglo XX. La relijión natural se presenta en un contexto de desarrollo de los estudios filosóficos en el Perú decimonónico y representa un aporte importante dentro de la historiografía del pensamiento de González Vigil. Por ello, en este artículo nos centraremos en presentar una pequeña síntesis del escrito, en dos aspectos muy importantes, en relación con su estructura morfológica y su estructuctura conceptual. Previamente dedicaremos unas líneas a su biografía y bibliografía.

Con la presentación de esta síntesis de la obra queremos revalorizar el pensamiento de Francisco de Paula González Vigil, para darle la importancia debida y aportar a la bibliografía del pensamiento filosófico peruano, 
y de este modo contribuir en la construcción de nuestra memoria, historia e identidad.

\section{Francisco de Paula González Vigil}

Francisco de Paula González Vigil nació de don Joaquín González Vigil y doña Micaela Yáñez, en la ciudad de Tacna, el 13 de setiembre de 1792. Desde muy joven se desenvolvió en el ámbito académico y el 13 de julio de 1803 obtuvo una beca en el Colegio del Seminario Conciliar de San Jerónimo de Arequipa. Los estudios en la Universidad San Antonio Abad del Cusco lo llevaron a graduarse como doctor en Teología.

Posteriormente regresó a su ciudad natal, donde cursó estudios de Derecho Natural con el presbítero doctor Juan José de la Fuente y Bustamante. Estos estudios serían trascendentales para orientar el norte del pensamiento de González Vigil y dejaron en él una huella imborrable. En 1815 decidió entrar al Seminario Mayor en Arequipa y se ordenó de clérigo en diciembre de 1818. A partir de la fecha regentó la cátedra de Teología en el Seminario de Arequipa.

Por situaciones personales regresó a Tacna el 8 de marzo de 1823. A partir de 1826 inició su actividad política. Se desenvolvió con gran ahínco, pues fue elegido diputado por la ciudad de Arica al Segundo Congreso Constituyente, que por cuestiones coyunturales no fue instalado. En estas circunstancias tuvo desavenencias con el general José de San Martín y se vio en la imperiosa necesidad de viajar a Chile.

Solucionadas las discrepancias, y habiéndose el general San Martin retirado del Perú, fue elegido diputado por Arica. Perteneció a la mayoría que eligió como presidente de la República al general La Mar.

Años más tarde, enfermó del pecho y convaleció en Miraflores. Luego viajó a Quillota y Concepción, en Chile, con la esperanza de recurarse rápidamente.

De regreso en Perú, fue nombrado en 1831 rector del Colegio de Arequipa. Al año siguiente se graduó de doctor en Jurisprudencia en la Universidad San Agustín. Fue miembro fundador de la Academia Lauretana.

Para la legislatura de 1832 fue elegido diputado por Tacna. Al haber presenciado los acontecimientos deleznables relacionados con el presidente Gamarra, su alto grado de conciencia y moral lo llevaron a acusar al mandatario y lo exhortó a que dejara el cargo de manera inmediata. En 1833 y 1834 presidió la Convención Nacional, para las legislaturas de los meses de setiembre y julio, respectivamente.

De 1836 a 1838 llevó la dirección de la Biblioteca Nacional, cargo que retomó en 1845 hasta los últimos días de su vida. En 1848 publicó su más grande obra, Defensa de la autoridad de los gobiernos y de los obispos 
contra las pretensiones de la curia romana, que tardó diez años en concluir. Luego de dicha publicación, en 1853, fue condenado y excomulgado por Pío IX a través del Breve Papal del 10 de junio, fecha a partir de la cual colgó los hábitos.

Falleció el 9 de junio de 1875 a las 6:50 de la mañana.

\section{Datos bibliográficos}

«La obra de Vigil [...] tuvo como objetivo: defender la libertad en sus más esenciales manifestaciones, la conciencia y la de opinión, contra la intolerancia política y religiosa» (López 1950: 24). Este propósito le trajo gran cantidad de dificultades; pese a ello, no se detuvo en su afán por luchar contra todo aquello que quita libertades al hombre y genera desigualdad.

Entre sus textos más importantes tenemos:

- A sus conciudadanos el diputado Vigil.

- Adiciones a la defensa de la autoridad de los gobiernos contra las pretensiones de la curia romana

- Apéndice al opúsculo sobre Mortará.

- Carta al Papa y análisis el Breve de 10 de junio.

- Cartas al Papa Pío IX, con varios documentos al caso. A la juventud americana.

- Catecismo patriótico. Para el uso de la Escuelas municipales de la ciudad del Callao.

- Catecismo patriótico para el uso de las escuelas municipales de la República.

- Compendio de la obra intitulada Los jesuitas, presentados en cuadros históricos, sobre las correspondientes pruebas, y con reflexiones al caso, especialmente en sus cosas de América.

- De la libertad civil de cultos, sin religión del Estado.

- De la tolerancia civil de cultos con religión del Estado.

- Diálogo sobre la existencia de Dios.

- Educación y sociedad.

- Importancia de la educación del bello sexo.

- Importancia de las asociaciones.

- Impugnación de un folleto que tiene por examen comparativo de la monarquía y de la república.

- Manual de derecho público-eclesiástico para uso de la juventud americana.

- Opúsculo sobre el principado político de Romano Pontífice.

- Opúsculos sociales y políticos dedicados a la juventud americana. 
- Paz perpetua en América o federación americana.

- La relijión natural.

Su participación en los diarios de circulación de su contexto fue también abundante. Escribió en:

- El Correo del Perú (Lima).

- La Tacora (Tacna).

- El Progresista.

- La Revista del Sur (Tacna).

- El Constitucional'.

- La América.

En líneas generales, encontramos en Vigil a un autor completo y muy comprometido con su sociedad, su cultura, en suma, con su país. Así tenemos las investigaciones de Manuel González Prada, Jorge Basadre, Manuel Mejía Valera, Augusto Salazar Bondy, Guillermo Leguía o la del catedrático de la Universidad de Navarra Marcelino R. Cuesta, uno de sus últimos investigadores. También se interesaron en la obra de este insigne filósofo instituciones como el Instituto Nacional de Cultura y la Biblioteca Nacional.

\section{Texto inédito La relijión natural}

\section{Estructura morfológica del texto}

El manuscrito consta de un compendio y una segunda parte, los que sumados dan 133 pliegos numerados, doblados en folios (cuatro páginas de 26 por $39 \mathrm{~cm}$ ), con un promedio de 44 líneas por página, incluyendo las notas a pie de página. La regularidad del trazo y la casi ausencia de enmendaduras indicaría que se trata de una manuscrito final, listo para la imprenta.

Contiene, como lo dice Vigil, «refutando y desacreditando en los cinco primeros [capítulos] las historias y los dogmas que venían de la revelación divina, según esa enseñanza. Trabajo ímprobo y prolijo para llegar [...] a la religión natural (González Vigil: folio).

Sobre este texto, González Prada, en el artículo titulado «Vijil» de Pájinas libres, nos dice: «Deja inédita una obra capital en que, apartándose de cuestiones canónicas i curialísticas, se muestra francamente racionalista i refuta uno por uno todos los dogmas católicos, desde el pecado orijinal hasta la divinidad de Jesucristo» (González Prada 1893: 20).

1 En este diario, González Vigil escribe alguno de sus opúsculos 
Además, González Prada supone el impacto que hubiera producido esta obra: «Publicado hoi [1890], a los veinte o veinticinco años d' escrito, después de los profundos trabajos emprendidos por los alemanes, ingleses i franceses, el libro produciría entre los eruditos i exéjetas europeos el mismo efecto que la resurrección de un hombre muerto en el siglo XV|» (González Prada 1893: 25).

Jorge Basadre nos dice, refiriéndose a González Prada en relación con Vigil: «Un escritor tan afín a él [Vigil] como González Prada, sin mengua de su respeto, llegó a escribir en 1890 que, ante su más valioso escrito el inédito acerca de La religión natural, "El lector menos maligno disfruta el placer de sonreírse, ya que no tiene la felicidad de convencerse"» (Basadre 1977: 63).

Esta obra se divide en un prólogo y una introducción. Desarrolla toda su argumentación en contra del dogmatismo eclesial en los cinco primeros capítulos: luego presenta un epílogo y finalmente el capítulo sexto, que refiere el desarrollo de la religión natural. El primer capítulo lleva por título «La revelación»; el segundo, «Doctrinas e historias del Antiguo Testamento»; el tercero, «Doctrinas e historias del Nuevo Testamento»; el cuarto, «La Iglesia y sus instituciones»; $y$, finalmente, el quinto, «El primado de la Iglesia».

\section{Estructura conceptual}

El texto inédito La relijión natural, visto semánticamente, consta de dos partes. La primera comprende desde el prólogo hasta el epílogo, y es un desarrollo pormenorizado de un conjunto de refutaciones que pretenden tirar por el suelo la actitud dogmática de la Iglesia católica. En la segunda parte, que comprende el capítulo sexto (desarrollado luego del epílogo), Vigil sustenta las bases por las que se debe regresar a un cristianismo primitivo, cuyos fundamentos se encuentran en la práctica de la vida cristiana desde las enseñanzas de Jesucristo.

\section{En contra del dogmatismo eclesial}

El análisis del dogmatismo católico está basado en elementos racionales, que han sido desenvueltos a partir de su formación humanista. Para Vigil, la razón es el medio que permite examinar los conocimientos, de modo que se puedan establecer si son auténticos o pura cháchara sin fundamentos.

A partir de esta concepción racional, examina la revelación y encuentra que los dos dogmas fundamentales en los que se sostiene todo el edificio teológico dogmático está en flagrante contradicción con los principios fundamentales que caracterizan a Dios, que son su ser bueno y justo. 
Estos dos principios fundamentales se contradicen tanto con el pecado original como con la existencia del sufrimiento eterno del infierno.

A partir de la refutación de estos principios, Vigil recorre todo el Antiguo Testamento y encuentra aspectos que contradicen los dos primeros principios. Lo mismo sucede en el análisis que realiza del Nuevo Testamento, en donde examina los misterios y los libros neotestamentarios hasta el Apocalipsis; encuentra razones suficientes para demostrar que no han sido inspirados por Dios. Las cuestiones de la revelación y la inspiración divina quedan para él sin un sustento que se mantenga de pie para soportar el edificio dogmático de la fe católica.

Además, estudia y critica la Iglesia, sus sacramentos, su historia, sus errores y aciertos, puesto que, junto con los personajes desdeñables, también aparecen los respetables, que siguieron las enseñanzas de Jesucristo desde las fuentes mismas, alejándose de toda pretensión de gloria y veneración humana.

La crítica mordaz que presenta González Vigil de los pontificados es la pretensión de sentirse dueños de la verdad y por tal motivo presentar dogmas, y con ello oponerse radicalmente a todo lo que significa el progreso para el hombre, oponerse a la ciencia y a aquello que se niegue a aceptar la voluntad de los papas.

Para Vigil, la Iglesia considera que la igualdad y la libertad son origen de monstruos que contradicen el derecho del Creador. «La palabra libertad es malsonante a los oídos pontificios», indica Vigil (González Vigil: folio 17a). Es decir, todo aquello que la Iglesia considera que aleja al hombre de Dios es dado como pernicioso. De este modo, el progreso, así como todo lo que se opone al recto camino de la providencia, debe evitarse y rechazarse.

La actitud de Vigil no es negativa, puesto que Dios ha prodigado a muchos hombres para que muestren a la Iglesia sus errores y puedan cambiar. Se han dado pasos en pro de corregir los yerros que se cometen al interior de la Iglesia, pero, como afirma el autor, aún falta mucho.

Finalmente, la crítica que elabora González Vigil es sobre la actitud del Papa de ser rey. Critica fuertemente la pretensión de no equivocarse; lo llama a la conversión, a darse cuenta de la vida de Jesús, a que caigan en cuenta de que la única corona que deben abrazar es la de espinas, y que el reino que deben buscar es con Dios y no con el mundo. Por ello dice: «retractaos cuanto habéis condenado de los gobiernos y de los obispos [...] Despojaos de todo lo civil» (González Vigil: folio 17b). 


\section{En busca de la religión natural}

Para Francisco de Paula González Vigil, la religión natural es aquella que se halla al alcance de todos los hombres, puesto que es capaz de, a través de la luz natural de la razón, ser aceptada por todos.

El primer aspecto de esta religión natural comienza por entender que Dios se manifiesta en cada uno de los aspectos de la vida del hombre. No hay que ser un iluminado ni mucho menos un sabio para captar la presencia de Dios en la vida diaria.

Esta actitud religiosa de entender a Dios en la vida misma está acompañada de lo que cada persona debe realizar para prodigarse bienestar. Para nuestro autor, el hombre debe buscar para sí todo aquello que lo ayude a realizarse como ser racional. Es decir, a partir de la razón, el ser humano buscará todo aquello que le conviene y le prodiga salud y bienestar. Por ello, afirma que cada persona debe obrar según dicta la razón, y sus obras lo llevarán a vivir en armonía con los demás y consigo mismo.

A partir de esta actitud racional, González Vigil se propone inculcar que se moderen las pasiones y se reforme el corazón. La religión debe ser solo práctica, sin dogmas que aten y esclavicen a los fieles.

La práctica religiosa está sustentada en máximas que todos racionalmente entienden y aceptan, como: «Haz a los demás lo que quisieras que ellos te hagan, en lugar de no hagas a otros lo que no quieres que te hagan» (González Vigil: folio 30a). A partir de esta máxima, González Vigil orienta el accionar de todas las personas, puesto que piensa que nadie desea el mal para sí mismo.

Frente a la posición católica que mantiene dogmas que están en contra de la naturaleza de Dios, González Vigil propone el camino de la religión natural que lleva la moralidad por buen camino. Propugna el matrimonio como sustento de la armonía del hogar, la moderación en el trato y los negocios, la tolerancia con las doctrinas diferentes, el amor a todos los hombres y, sobre todo, la adoración en espíritu y verdad.

Además, la religión natural va de la mano con el espíritu del progreso y la libertad, y motiva en las personas su propio desarrollo, que lo llevará a una vida superior.

Para Francisco de Paula González Vigil, el cristianismo no está lejos de la religión natural; todo lo contrario, son muy parecidos, pero se encuentran diferenciados por aspectos dogmáticos: los dogmas, en lugar de ayudar al desarrollo de la fe cristiana, la han empobrecido. Si contrastáramos el cristianismo actual con el de los orígenes, se notarían claramente las diferencias, puesto que los primeros cristianos «predicaban máximas, cuya 
letra se hallaba estampada en los corazones, máximas consoladoras para todos los desgraciados» (González Vigil: folio 112).

Nuestro autor no quiere fundar otra religión: quiere que se vuelva a las máximas fundamentales que se practicaban al principio de la fe cristiana, basándose en principios que todos tiene en el corazón, de modo que, sin reparos, todos puedan «adorar a un solo Dios, el único Dios, al Dios de la naturaleza» (González Vigil: folio 113b).

«En todos los actos de la vida pública y privada se dará culto a Dios, porque se cumplirán los deberes impuestos por Dios y los impuestos por los hombres conforme a las intenciones de Dios» (González Vigil: folio 13c). Con ello Vigil afirma que la voluntad de Dios es la práctica de los deberes que cada uno tiene que cumplir.

\section{A manera de conclusión}

La vida de Francisco de Paula González Vigil se caracteriza por la coherencia. Sus palabras reflejan sus actos. Su obra retrata su profundo compromiso con la libertad y la igualdad, de modo que podemos observar en sus textos todas las necesidades apremiantes de su época.

El texto inédito La relijión natural es una exhortación para que la curia romana se dé cuenta de los errores en los que está cayendo y pueda volver al camino correcto que trazó Jesucristo desde el origen. Además, presenta la visión que tenía González Vigil de la práctica religiosa, una práctica perniciosa que desea cambiar y volverla a sus orígenes. Finalmente, el texto inédito muestra la intención de González Vigil de ayudar a reformar la Iglesia católica, que se encuentra en franca decadencia. 


\section{REFERENCIAS BIBLIOGRÁFICAS}

BASADRE, Jorge (2005). Historia de la República del Perú. Lima: Orbis Ventures.

(1977). «La nueva actualidad de Vigil». En Fénix, nro.

21, pp. 62-74.

CARVAJAL, Néstor (1968). Francisco de Paula González Vigil. Lima: Editorial Tacna.

GALVÁN, Luis (1961) La vida ejemplar de Francisco de Paula González Vigil. Lima: Imprenta El Cóndor.

GONZÁLEZ, Carlos (1961). Francisco de Paula González Vigil. Lima: Escuela de Artes Gráficas del Politécnico Nacional Superior José Pardo.

GONZÁLEZ PRADA, Manuel (1893). Pájinas libres. Lima: Peisa.

GONZÁLEZ VIGIL, Francisco de Paula (1973). Educación y sociedad. Lima: Instituto Nacional de Cultura.

(1976). Importancia de la educación del bello sexo. Lima: Instituto Nacional de Cultura,

(s. f.) La relijión natural. Texto manuscrito.

LAZO, Raimundo (1943?). Vigil, Palma, González Prada: evocaciones históricas de la Biblioteca Nacional de Lima. La Habana: s. d.

LITUMA, Luis (1964). Luna Pizarro, González Vigil. Lima: Editorial Universitaria.

LÓPEZ ALBÚJAR, Carlos (1950). Semblanza de Francisco de Paula González Vigil. Lima: Talleres Gráficos G. A. Quiroz.

REVOREDO, Alberto (2007, 25 de marzo). «Un histórico manuscrito». En El Comercio, p. C22. 